\title{
Cultural and Morphological Variability in Phomopsis vexans (Sacc. \& Syd.) Harter Causing Fruit Rot of Brinjal
}

\author{
Moakala Jamir ${ }^{*}$, T. Rajesh ${ }^{1}$, R.K. Tombisana Devi ${ }^{1}$, D. Majumder ${ }^{1}$, Kennedy \\ Ningthoujam $^{1}$ and L. Hemochandra ${ }^{2}$
}

School of Crop Protection, School of Social Sciences, College of Post-Graduate Studies, Central Agricultural University (Imphal), Umiam, Meghalaya-793103, India

*Corresponding author

\section{A B S T R A C T}

\section{Keywords \\ Brinjal fruit rot, Phomopsis vexans, Conidia, Variability, Meghalaya}

Article Info

Accepted: 20 June 2018 Available Online: 10 July 2018

\begin{abstract}
Brinjal (Solanum melongena L.) also known as eggplant is a popular vegetable crop grown worldwide. The most destructive and important disease on brinjal is fruit rot incited by the fungus, Phomopsis vexans (Sacc. \& Syd.) Harter. The fruit rot adversely affects the fruit quality and quantity reducing the market value. A total of 20 isolates of $P$. vexans were obtained from Ri-Bhoi district of Meghalaya. All the isolates were found pathogenic to brinjal. The isolates showed significant variations in colony colour, shape, zonation and consistency in the media viz., Potato dextrose agar (PDA), Malt extract agar (MEA), Richard's synthetic agar (RSA) and Czapek's dox agar (CDA). The maximum average growth of all the isolates was supported by PDA medium $(8.58 \mathrm{~cm})$. The highest biomass production was recorded in isolate Pv21 (393 mg) and the lowest in isolate Pv12 (163 mg). Alpha $(\alpha)$ and beta $(\beta)$ conidia were also observed in all the isolates. Among the isolates, $\alpha$ conidia size was maximum in isolate Pv5 $(8.9 \times 3.4 \mu \mathrm{m})$ and minimum in isolate Pv15 $(4.9 \times 2.8 \mu \mathrm{m})$, whereas $\beta$ conidia size was maximum in isolate Pv17 $(23.56 \times 2.26 \mu \mathrm{m})$ and minimum in isolate Pv4 (14.88x1.27).
\end{abstract}

\section{Introduction}

Brinjal (Solanum melongena L.) also known as eggplant or garden egg a member of Solanaceae family is a popular vegetable crop grown almost worldwide. In India, it is one of the most common vegetable crops grown throughout the country except higher altitudes. The fruits of eggplant are very common in Indian daily dietary as it associates good nutritional value (Ribeiro et al., 1998) and therapeutic properties (Reis et al., 2007).
Several diseases invading the crop are the major constraints for limited brinjal production and productivity. The most destructive and important disease on brinjal are Brinjal leaf blight and fruit rot incited by the fungus, Phomopsis vexans (Sacc. \& Syd.) Harter (Edgerton and Moreland, 1921). The fruit rot distinctively is the most destructive phase of disease which damages the fruit partially or completely in the field as well as during transit. On the fruits, the disease appears as minute sunken greyish spots with 
brownish halo. These spots form large rotten areas on which pycnidia develop, which are arranged concentrically. It is a major concern as it reduces yield and marketable value of the crop nearly 20 to 30 per cent (Jain and Bhatnagar, 1980; Kaur et al., 1985). In India losses to the extent of 10-20 per cent have been reported (Panwar et al., 1970).

Phomopsis vexans is a pycnidial fungus, easily seed borne and producing large numbers of conidia. It produces $\alpha$ and $\beta$ conidia which are characteristic to the genus Phomopsis (Boerema et al., 2004).

The $\alpha$ conidia produced are hyaline, onecelled, and sub-cylindrical while, $\beta$ conidia (stylospores) are filiform, curved, hyaline and aseptate (Singh, 1992).

$P$. vexans is highly versatile to changing environmental conditions and shows high variability across different agro-climatic regions. Therefore, in order to document the changes occurring in populations and individuals, variability studies are important as it indicates different pathotypes and may open up a new avenue for disease management in the future. Variation in pathogen can be generally detected by their cultural and morphological characters.

\section{Materials and Methods}

\section{Collection of disease samples}

Phomopsis leaf blight and fruit rot infected samples were collected from brinjal growing region in the $\mathrm{Ri}$-Bhoi district of Meghalaya.

The infected leaves and fruits samples were plucked and kept in polythene bags with labels. They were brought to laboratory for microscopic observation and later kept at $4{ }^{\circ} \mathrm{C}$ for further studies.

\section{Isolation and identification of Phomopsis vexans isolates}

The fungus was isolated from the tissues of characteristic leaf blight and fruit rot symptom. Small fragment cuts of $2-3 \mathrm{~mm}$ size were made followed by surface sterilizing in $1 \%$ sodium hypochlorite for 1 minute and then rinsing thrice with sterile distilled water. The pieces were aseptically transferred into Petri plates containing Potato dextrose agar (PDA) medium and the plates were incubated at $27 \pm 2^{\circ} \mathrm{C}$ for seven days. To obtain pure culture, the growing edges of fungal hyphal mycelium developing from the diseased tissue were cut into discs and then transferred aseptically to Petri plates containing fresh PDA medium. The pure culture was also preserved in PDA medium slants at $4^{\circ} \mathrm{C}$. The pathogen was identified on the basis of morphological and cultural characters studied.

\section{Pathogenicity test}

The ability of the isolates to induce fruit rot in brinjal was assessed on fresh fruits by in vitro detached fruit technique (Akhtar and Chaube, 2006). Fruits free of defects or injury, uniform in size and colour were selected afterwhich surface sterilized with $1 \%$ sodium hypochlorite and washed in three changes of sterile distilled water. With the aid of sterile cork borer, a cylindrical hole was dug into the fruits and a five mm diameter mycelial disc of fifteen day old culture was placed into the bored hole. The inoculated fruits were incubated at $27 \pm 2^{\circ} \mathrm{C}$ until the disease symptoms started to develop.

\section{Cultural and morphological variability studies}

The cultural characteristics of the isolates were studied in four different media viz., PDA, Malt extract Agar (MEA), Richards synthetic Agar (RSA) and Czapek's dox Agar. Mycelial 
disc $(5 \mathrm{~mm})$ was cut from seven day old actively growing culture isolates and inoculated at the centre of each plate. The inoculated plates were incubated at $27+2^{\circ} \mathrm{C}$ in the dark for seven days for studying mycelial characteristics such as colony type, shape, zonation, consistency whereas, for colony colour the plates were incubated for more than seven days. Three replications were maintained for each media.

\section{Effect of different solid media on growth of isolates of $P$. vexans}

The effect of above four media on the growth of the isolates were also checked and the growth was measured as colony diameter $(\mathrm{cm})$ which was recorded by averaging the linear growth of colony in two directions for each plate.

\section{Biomass}

Potato Dextrose Broth (PDB) adjusted to final $\mathrm{pH} 7$ was dispensed at $50 \mathrm{ml}$ each in $250 \mathrm{ml}$ capacity Erlenmeyer flask and then sterilized at $15 \mathrm{lbs}$ (p.s.i.) at $121.6{ }^{\circ} \mathrm{C}$ for 15 minutes. A five $\mathrm{mm}$ mycelial disc cut from actively growing seven day old culture was inoculated into the broth and incubated at $27 \pm 2^{\circ} \mathrm{C}$ for 12 days. Three replications for each isolate were maintained. At the end of the incubation mycelium mats were harvested and filtered through sterilized whatman filter paper no.1. The weight of dried filter paper was recorded before filtration $\left(\mathrm{W}_{1}\right)$. Filter paper along with the mycelia were dried in an electric oven at $60^{\circ} \mathrm{C}$ for 48 hours, cooled in a dessicator and weighed by using electronic balance $\left(\mathrm{W}_{2}\right)$. The net dry weight of mycelia (W) was calculated by deducting $\mathrm{W}_{1}$ from $\mathrm{W}_{2}$ i.e., $\mathrm{W}=$ $\mathrm{W}_{2}-\mathrm{W}_{1}$.

\section{Microscopic studies}

PDA was used as basal medium to observe the fruiting structure producing conidia of the isolates. In respect of conidial characteristics, the shape and size of conidia as well as number of guttulae were observed under $40 \mathrm{X}$ magnification using Leica compound microscope. Single pycnidium was picked from more than 15 day old culture and placed in a clean slide which was crushed with a needle and a drop of distilled water was put over it and covered by placing a cover slip. The measurement was done with Leica software version 1.8.0. The average lengths and breadths of 60 conidia from 20 isolates were recorded.

\section{Results and Discussion}

\section{Isolation and maintenance of different isolates of Phomopsis vexans}

The pathogen was isolated and the fungal cultures on purification showed white colour and fluffy type of mycelium, which gradually turned into greyish, greenish or brownish as the culture started to produce pycnidia. On repeated isolation, it was found the association of Phomopsis spp.

A total of twenty isolates were obtained and designated with isolate code as $\mathrm{Pv}$ according to their respective places of collection. The pathogen was identified by comparing with relevant literatures and by studying the cultural and morphological characters. The fungal isolate cultures were sub cultured frequently on PDA slants and kept in refrigerator at $4{ }^{\circ} \mathrm{C}$.

\section{Pathogenicity}

To prove Koch's postulate, the isolated pathogen were inoculated on healthy fruits and all the isolates tested were pathogenic on brinjal fruits. However, the isolates behaved differently for the ability to produce disease symptoms on fruits. Isolate Pv6 showed complete rotting symptom after 11 days of inoculation (Fig. 1). Typical symptoms of fruit 
rot of brinjal developed were similar to those described by Chowdhury and Hasija (1979), Datar (1983)

\section{Cultural and morphological variability}

The cultural characteristics of few important isolates are presented in Figure 2. The following observations were made on colony type, colour, shape, zonation and colony consistency.

Type: On PDA and MEA, fluffy type of mycelium was observed for all the isolates, whereas fluffy and slightly fluffy (10 isolates each) were produced in RSA. In CDA, fluffy (13 isolates) and slightly fluffy ( 7 isolates) type of mycelium was observed.

Colony colour: On PDA, colony colour recorded were greenish (9 isolates), greyish (isolate Pv3 and Pv12) and whitish (9 isolates). On MEA, the colony colour observed to be whitish (13 isolates), greenish (5 isolates) and greyish (isolate Pv3 and Pv12). The colony colour on RSA varied from whitish (7 isolates), greenish (10 isolates) and brownish (isolate Pv3, Pv6 and Pv12). Likewise on CDA, colony colour varied from whitish ( 8 isolates) to greenish (10 isolates) and brownish (isolate Pv3 and Pv6).

Shape: On PDA and MEA majority of the isolates showed irregular shape. However isolates Pv4, Pv7 and Pv21 in PDA and isolates Pv7, Pv8, Pv17, Pv18, and Pv19 in MEA were observed to be of circular shape. When grown in RSA and CDA, twelve isolates each showed irregular and eight isolates each showed circular colony shape.

Zonation: On PDA and MEA majority of the isolates produced distinct zonation except isolate Pv13 in PDA and isolate Pv3, Pv12 and Pv13 in MEA showed indistinct zonation. Likewise on RSA and CDA, the zonation were distinct in majority of the isolates whereas isolate Pv3, Pv4 and Pv12 in RSA and isolate Pv3 and Pv12 in CDA showed indistinct zonation.

Consistency: The isolates when grown on PDA, MEA and RSA, the colony was observed to be compact and thick consistency. However, isolate Pv3, Pv7 and Pv16 in RSA showed compact and thin consistency. On CDA, the colony consistency varied from compact and thick (9 isolates) to compact and thin (8 isolates) to loose and thin in isolate Pv5, Pv7 and Pv21.

The twenty isolates did differ in different prospect such as type of colony, colour, zonation, consistency, such variations have been reported by (Islam et al., 2009; Rohini et al., 2016).

Fig.1 Pathogenicity test (In vitro detached fruit technique)

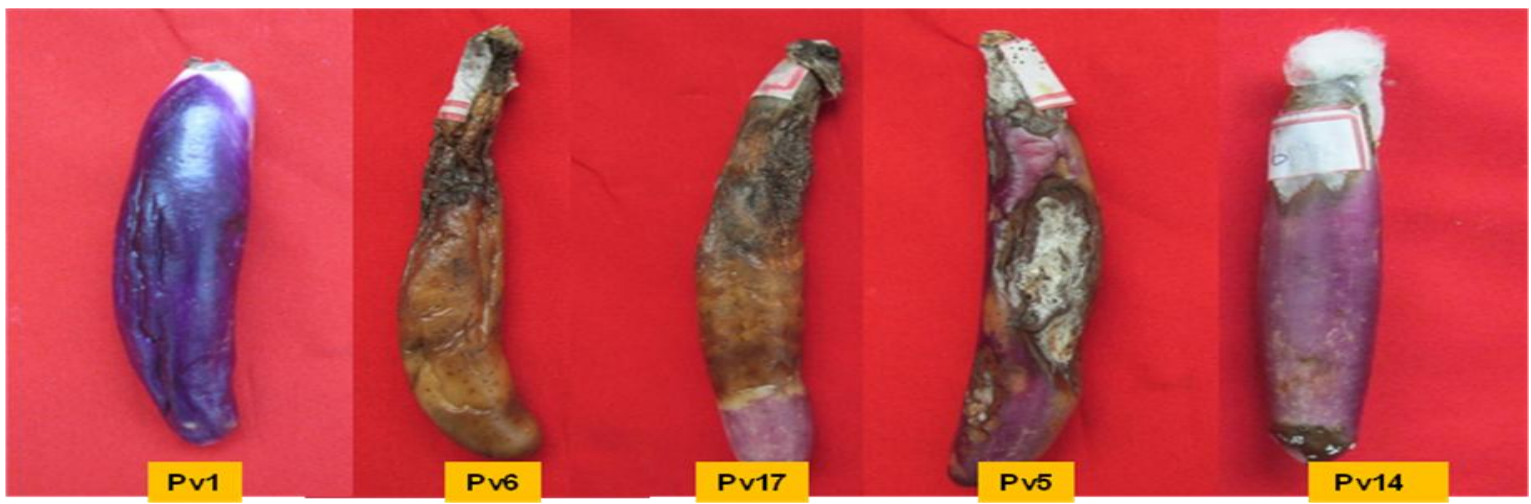


Fig.2 Cultural characteristics of $P$. vexans isolates

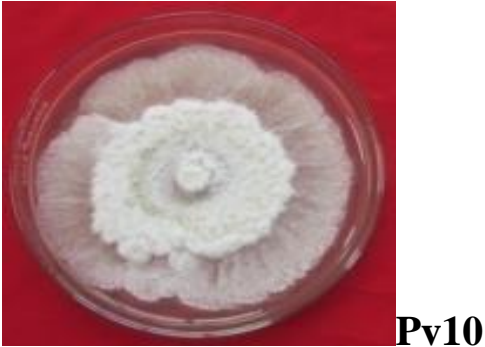

compact and thick

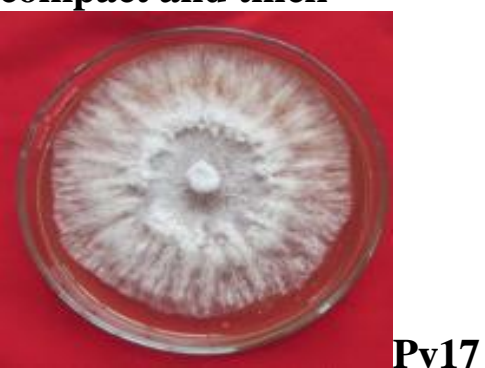

circular shape

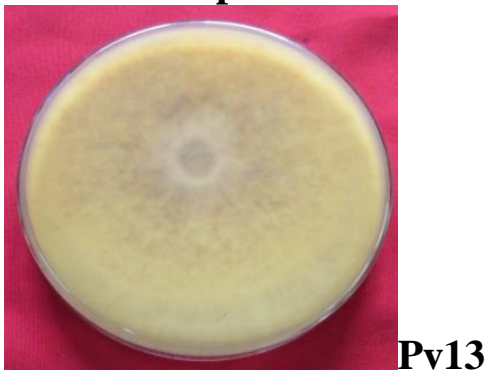

indistinct zonation

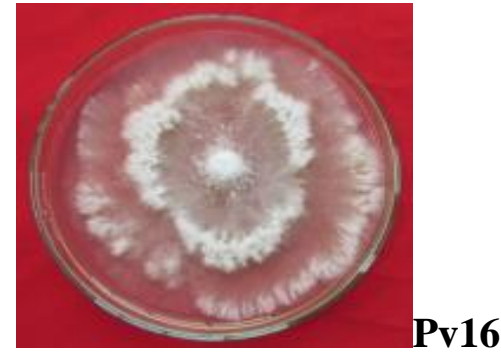

compact and thin

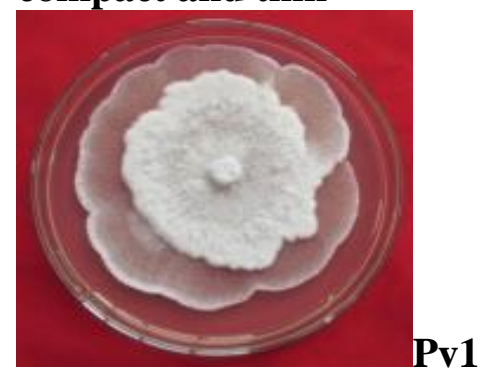

irregular shape

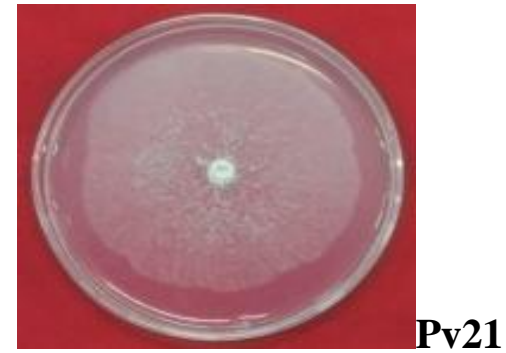

loose and thin

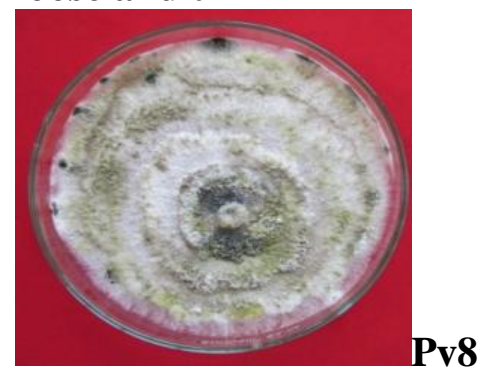

greenish colour

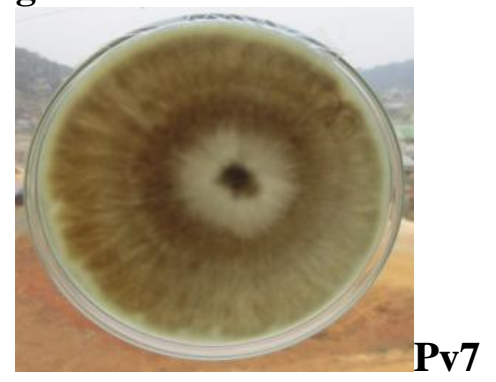

distinct zonation

Fig.3 Average colony diameter $(\mathrm{cm})$ in four different media

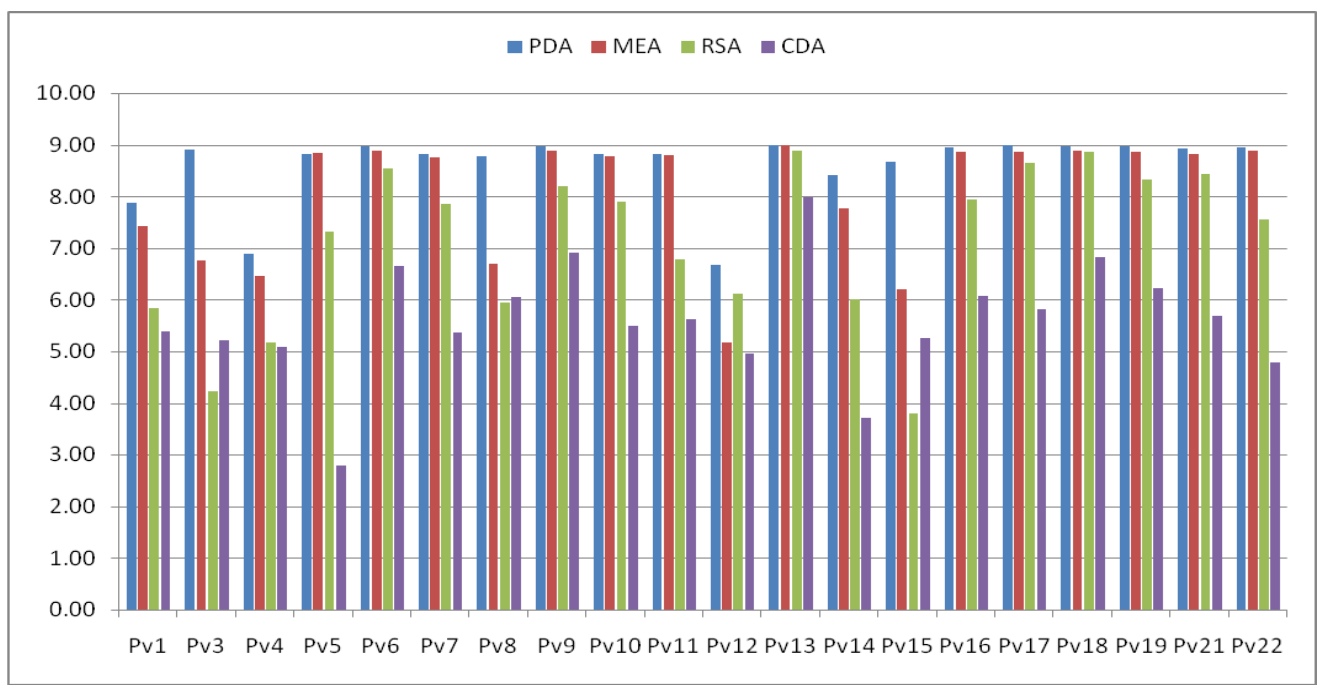


Fig.4 Spores of $P$. vexans (a) $\alpha$ conidia (b) $\beta$ conidia
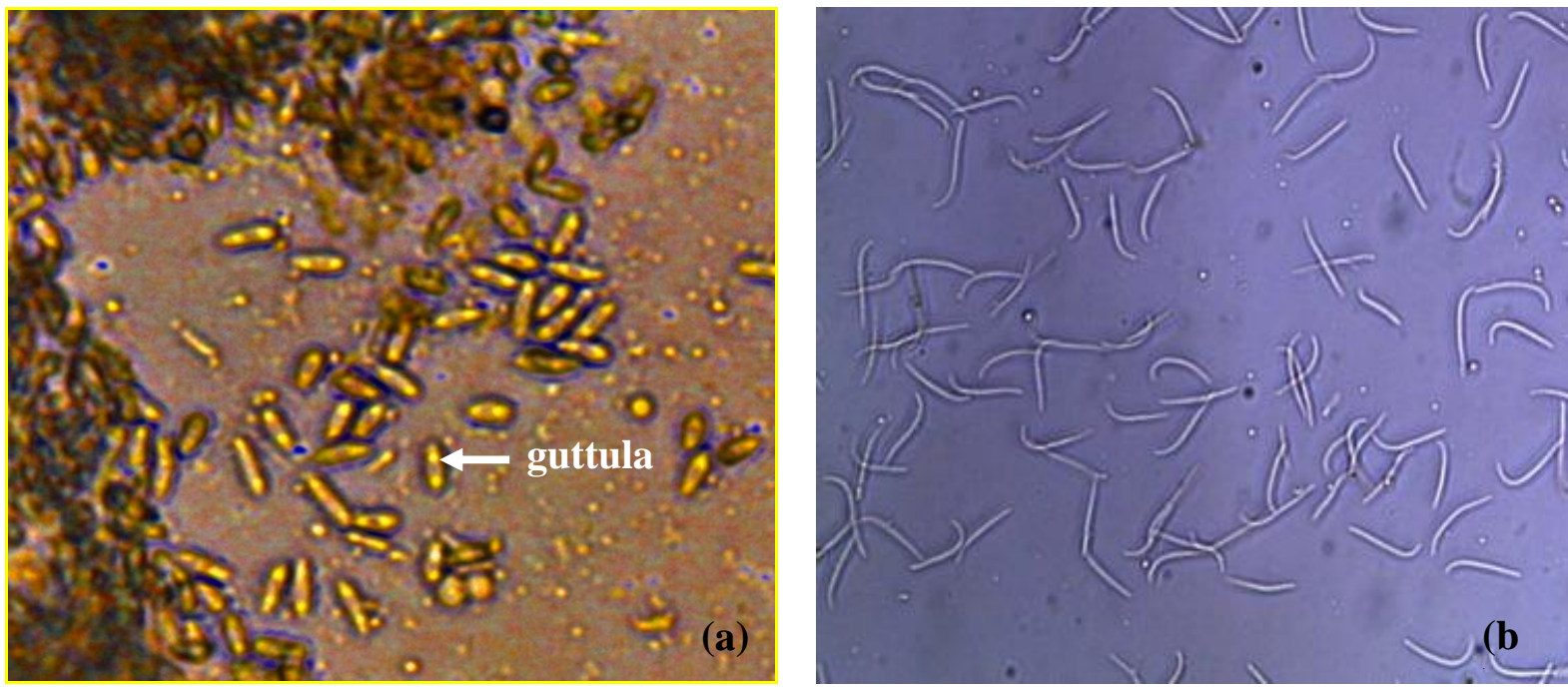

Table.1 Microscopic identification of $P$. vexans

\begin{tabular}{|c|c|c|c|c|c|}
\hline Isolates & \multicolumn{3}{|c|}{ Alpha conidia $(\alpha)$} & \multicolumn{2}{c|}{ Beta conidia $(\beta)$} \\
\hline & Guttulae & Shape & Size $(\boldsymbol{\mu m})$ & Size $(\boldsymbol{\mu m})$ & Shape \\
\hline Pv1 & 2 & Sub-cylindrical & $6.4 \times 2.4$ & $17.26 \times 1.82$ & Curved \\
\hline Pv3 & 2 & Sub-cylindrical & $5.9 \times 2.1$ & $19.02 \times 1.54$ & Curved \\
\hline Pv4 & 2 & Sub-cylindrical & $6.8 \times 2.6$ & $14.88 \times 1.27$ & Curved \\
\hline Pv5 & $1-2$ & Sub-cylindrical & $8.9 \times 3.4$ & $21.74 \times 1.82$ & Curved \\
\hline Pv6 & 2 & Sub-cylindrical & $6.7 \times 2.6$ & $20.94 \times 1.57$ & Filiform \\
\hline Pv7 & $1-2$ & Sub-cylindrical & $7.0 \times 2.3$ & $18.83 \times 1.67$ & Curved \\
\hline Pv8 & 2 & Sub-cylindrical & $7.1 \times 2.5$ & $20.22 \times 2.24$ & Filiform \\
\hline Pv9 & 2 & Sub-cylindrical & $6.0 \times 2.3$ & $16.84 \times 1.98$ & Curved \\
\hline Pv10 & 2 & Sub-cylindrical & $8.3 \times 3.1$ & $19.83 \times 1.86$ & Filiform \\
\hline Pv11 & $2-3$ & Sub-cylindrical & $8.1 \times 3.2$ & $21.36 \times 1.91$ & Curved \\
\hline Pv12 & 2 & Sub-cylindrical & $5.8 \times 2.5$ & $19.32 \times 1.78$ & Curved \\
\hline Pv13 & 2 & Sub-cylindrical & $6.8 \times 2.2$ & $18.69 \times 1.65$ & Curved \\
\hline Pv14 & 2 & Sub-cylindrical & $8.4 \times 2.4$ & $17.48 \times 1.16$ & Curved \\
\hline Pv15 & 2 & Sub-cylindrical & $4.9 \times 2.8$ & $15.32 \times 1.62$ & Curved \\
\hline Pv16 & 2 & Sub-cylindrical & $7.4 \times 2.4$ & $21.64 \times 1.18$ & Curved \\
\hline Pv17 & 2 & Sub-cylindrical & $6.4 \times 2.5$ & $23.56 \times 2.26$ & Filiform \\
\hline Pv18 & 2 & Sub-cylindrical & $5.7 \times 2.4$ & $19.84 \times 1.91$ & Filiform \\
\hline Pv19 & 2 & Sub-cylindrical & $6.0 \times 2.3$ & $22.43 \times 1.70$ & Filiform \\
\hline Pv21 & $1-2$ & Sub-cylindrical & $7.8 \times 3.2$ & $19.83 \times 1.84$ & Curved \\
\hline Pv22 & 2 & Sub-cylindrical & $6.9 \times 2.7$ & $18.58 \times 2.10$ & Curved \\
\hline & & & & & \\
\hline
\end{tabular}


Effect of different culture media on growth of different isolates of $P$. vexans

Nutrition plays an important role in growth of the fungus, the differential support of four different culture media on growth of the isolates of $P$. vexans are presented in (Fig. 3).

PDA supported the maximum growth of all the isolates. The maximum colony diameter $(9 \mathrm{~cm})$ was recorded in five isolates while the lowest diameter was recorded in isolate Pv12 $(6.67 \mathrm{~cm})$. In MEA, maximum colony diameter $(9 \mathrm{~cm})$ was recorded in isolate Pv13 followed by isolate Pv6 and Pv9 $(8.89 \mathrm{~cm})$. The minimum colony diameter was recorded in isolate Pv12 $(5.17 \mathrm{~cm})$. In RSA, the maximum colony diameter was observed in isolate Pv13 $(8.89 \mathrm{~cm})$ whereas the minimum diameter was found in isolate Pv15 $(3.79 \mathrm{~cm})$. The least growth of all the isolates was supported by CDA. In CDA, the maximum colony diameter was observed in isolate Pv13 $(7.99 \mathrm{~cm})$ whereas the lowest growth was found in isolate Pv5 $(2.78 \mathrm{~cm})$. A result similar was observed by Verma (1993) who recorded the highest mycelial growth of $P$. vexans on PDA.

\section{Biomass production}

The isolates differed considerably in biomass production in PDB. Maximum dry weight of $393 \mathrm{mg}$ was recorded with isolate Pv21 and minimum biomass of $163 \mathrm{mg}$ was produced by isolate Pv12. The study is conformity with Akhtar and Chaube (2006) who showed that the biomass production of 32 isolates varied from $20-353 \mathrm{mg}$

\section{Microscopic studies}

Two types of spores $\alpha$ and $\beta$ were observed from all the isolates Table 1 (Fig. 4). The shape and colour of $\alpha$ conidia recorded was sub-cylindrical and hyaline for all the isolates.
The $\beta$ conidia produced was hyaline for all the isolates; however variation in the shape was noticed. Of the twenty isolates curved shaped (14 isolates) and filiform (6 isolates) were observed.

Variation in the presence of guttulae (oil drop) in alpha conidia was evident. From the twenty isolates sixteen isolates were recorded with 2 guttulae while three isolates were recorded with 1-2 guttulae and in isolate Pv11, 2-3 guttulae was observed.

The size of $\alpha$ conidia varied from $4.9 \times 2.8$ $8.9 \times 3.4 \mu \mathrm{m}$ in which isolate Pv5 recorded the maximum length $(8.9 \mu \mathrm{m})$ followed by isolate Pv $10(8.3 \mu \mathrm{m})$ whereas minimum length $(4.9$ $\mu \mathrm{m})$ was recorded in isolate Pv15. The size of $\beta$ conidia ranged from $14.88 \times 1.27-23.56 \times 2.26$ $\mu \mathrm{m}$ where isolate Pv17 was observed with the maximum length of $23.56 \mu \mathrm{m}$ followed by Pv19 $(22.43 \mu \mathrm{m})$ whereas isolate Pv4 recorded the minimum length of $14.88 \mu \mathrm{m}$. The results show similarities with the conidial measurement reported by (Singh, 1992; Akhtar and Chaube, 2006).

In conclusion, the present work on cultural and morphological variability of $P$. vexans is the preliminary work which may be surely helpful for future studies on suitable management strategies of brinjal fruit rot.

\section{References}

Akhtar, J. and Chaube, H.S. (2006). Variability in Phomopsis blight pathogen [Phomopsis vexans (Sacc. \& Syd.) Harter]. Indian Phytopath., 59(4): 439-444.

Boerema, G.H., Gruyter, J., Noordeloos, M.E., and Hamers, M.E.C. (2004). Phoma identification manual Differentiation of specific and infraspecific taxa in culture. CABI Publishing, Wallingford, UK. 
Chowdhury, S.R. and Hasija, S.K. (1979). Phytopathological studies on Phomopsis vexans causing soft rot of brinjal fruits. Indian Phytopath., 32: 495-496.

Datar, V.V. (1983). Synergism of Fusarium moniliforme with Phomopsis vexans in causing brinjal fruit rot. Indian Phytopath., 36: 136.

Edgerton, C.W. and Moreland, C.C. (1921). Eggplant blight. Louisiana Agric. Exp. Stat. Bull., 178: 1-44.

Islam, M.R., Meah, M.B., Islam, M.R., Islam, M.M., and Faruq, A.N. (2009). Studies on some physiological aspects of Phomopsis vexans causing Phomopsis blight and fruit rot of Eggplant. J. Sher-e-Bangla Agric. Univ., 3(1): 96-103.

Jain, M.P. and Bhatnagar, M.K. (1980). Efficacy of certain chemicals in the control of fruit rot of brinjal. Pesticides 14: 27-28

Kaur, S., Kaur, R., Kaur, P., and Singh, D. (1985). Studies on wilt and fruit rot of brinjal caused by Fusarium semitectum. Indian Phytopathol., 38: 736-738.

Panwar, N.S., Chand, J.N., Singh, H., and Paracer, C.S. (1970). Phomopsis fruit rot of brinjal (S. melongena L.) in the
Punjab and viability of the fungus and role of seeds in the disease development. J. Res. P. A. U. Ludhiana, 7: 641-643.

Reis, A., Lopes, C.A., Moretti, C.L. et al (2007). Berinjela (Solanum melongena L.). Brasilia: Embrapa Horalicas. N.p. (Embrapa Hortalicas. Sistemas de Producao 3). Disponivel em:http://www.cnph.embrapa.br.

Ribeiro, C.S.C., Brune, S., and Reifchneider, F.J.B. (1998). Cultivo da berinjela.Brasilia:Embrapa Hortalica $\mathrm{s}$ p. 23.

Rohini, Gowtham, H.G., Hariprasad, P., and Niranjana. (2016). Cultural, morphological and physiological characterization of Phomopsis vexans isolates from different brinjal (Solanum melongena L.) growing regions of Karnataka, India. Int. J. Pharm. Bio. Sci., 7(3): 70-77.

Singh, R.S. (1992). Diseases of Vegetable crops, second edn. Oxford and IBH publishing company Pvt. Ltd. New Delhi, Bombay, Calcutta. pp. 119-121. Verma, R.K. (1993). Studies on Phomopsis blight of eggplant (Solanum melongena L.). $\mathrm{Ph} . \quad \mathrm{D}$. Thesis, Submitted to J. N. K. V. V., Jabalpur (M.P).

\section{How to cite this article:}

Moakala Jamir, T. Rajesh, R.K. Tombisana Devi, D. Majumder, Kennedy Ningthoujam and Hemochandra, L. 2018. Cultural and Morphological Variability in Phomopsis vexans (Sacc. \& Syd.) Harter Causing Fruit Rot of Brinjal. Int.J.Curr.Microbiol.App.Sci. 7(07): 2807-2814. doi: https://doi.org/10.20546/ijcmas.2018.707.328 